\title{
Assessing a carbon neutral building approach
}

\author{
M. Bendewald \& J. Brew \\ Rocky Mountain Institute (RMI), USA
}

\begin{abstract}
"One of nature's most critical cycles is the continual exchange of carbon dioxide and oxygen among plants and animals. This "recycling service" is provided by nature free of charge. But today carbon dioxide is building up in the atmosphere, due in part to combustion of fossil fuels. In effect, the capacity of the natural system to recycle carbon dioxide has been exceeded, just as overfishing can exceed the capacity of a fishery to replenish stocks. But what is especially important to realize is that there is no known alternative to nature's carbon cycle service". - Natural Capitalism (1999)

At Rocky Mountain Institute we have been developing ways to evaluate our built environment with regard to carrying capacity. Green Footstep ${ }^{\mathrm{TM}}$, a free online tool, is an outcome of these efforts.

The Green Footstep calculator is a building assessment tool using ecologically based assessment criteria. Most existing tools and assessment systems measure performance relative to a baseline case of "standard performance." Generally this equates to a code-compliant building and green performance is measured as a percentage reduction in a particular area, such as water or energy use. As a result, green buildings are rewarded for causing less environmental damage than typical buildings. However, these relative, rather than absolute, performance evaluations rarely make the connection to actual environmental impacts.

The Green Footstep tool brings forth building site ecology and ecological limits into the domain of building stakeholders and addresses the ecological challenges of our time.
\end{abstract}

Keywords: carbon, footprint, assessment tool, ecological limits, carrying capacity, building, design targets. 


\section{Measuring sustainability}

One way to measure progress toward an absolute measure of sustainability is with the ecological concepts of carrying capacity and ecosystem services. Carrying capacity refers to the maximum population of humans or animals that an environment can support without damaging that environment. When a population exceeds carrying capacity, this over-exploitation of resources and excessive waste generation places stress on the various ecological systems and they slowly begin to collapse. This phenomenon is known as "overshoot."

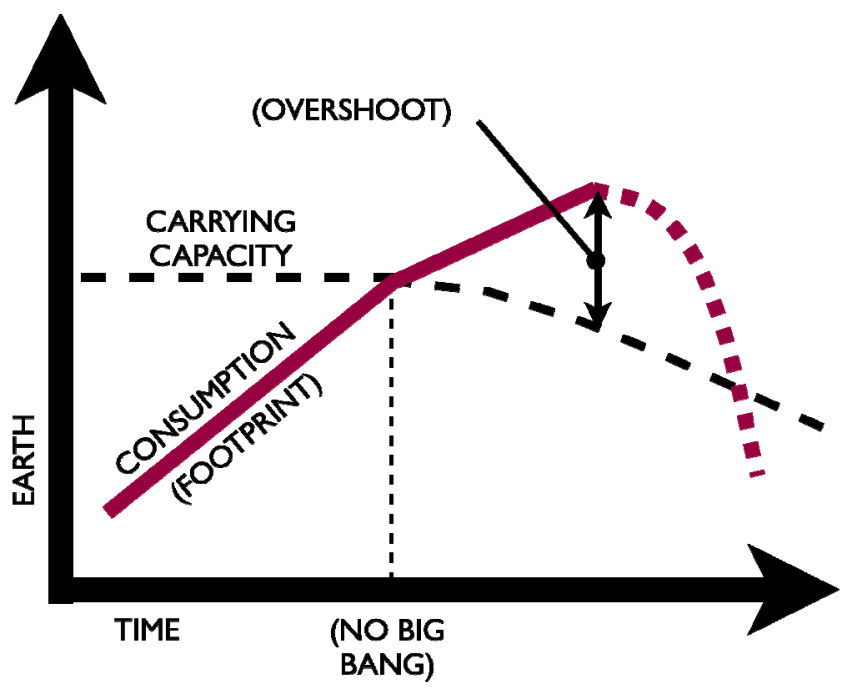

Figure 1: Concept of ecological “overshoot” Wackernagel and Rees [1].

Of particular concern with ecological overshoot of carrying capacity is the eventual decay of ecosystem services. These services can be seen as forming a life-support system, as they provide functions such as climate regulation, nutrient cycling, water purification, and food and fiber growth. Ecosystem services are immeasurably valuable and cannot be replaced. In 2005, the Ecosystem Millennium Assessment, formed by the United Nations, attempted to define ecosystem services in terms of human well-being. Figure 2 illustrates their results. Services ranging from the mundane (e.g., food growth) to the esoteric (e.g., spiritual services) each contribute to elements of well being, such as Security and Health.

In order to make an assessment of a building project with regard to carrying capacity, we need to determine the amount of ecosystem services we have to use. This estimate would provide us with a better sense of how we need to build our environment in order to live within the ecological limits of the earth. 


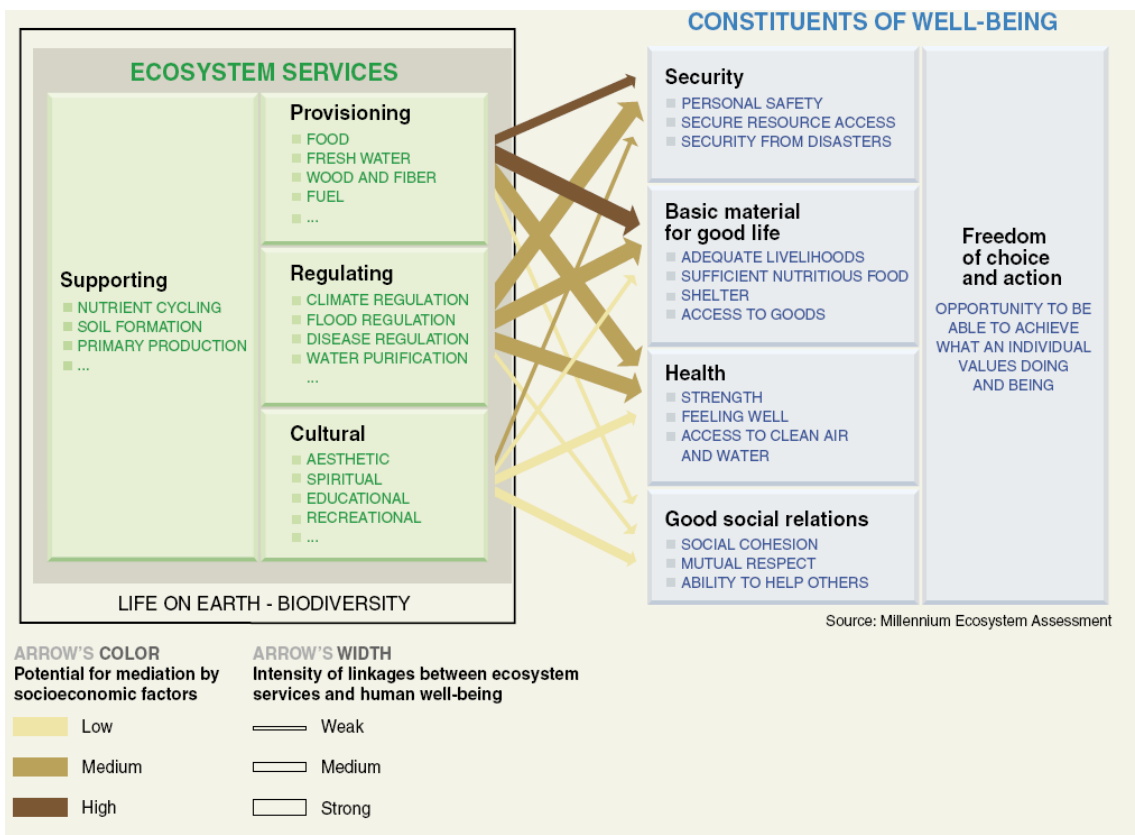

Figure 2: $\quad$ Millennium ecosystem assessment [2].

\section{Carbon and buildings}

While it can be difficult to assess ecosystems services, one of the most important is also relatively easy to measure: the global carbon cycle. Carbon is an abundant naturally occurring element. It can combine easily with other elements and is an integral part of the basic processes of life. Through the global carbon cycle, carbon is constantly moving between the atmosphere and the earth. There is a certain rate at which vegetative life, the ocean, and other carbon sinks remove (or sequester) carbon dioxide from the air. If this sequestration is at a lesser rate than global carbon dioxide emissions, carbon dioxide begins to accumulate in the atmosphere and creates the greenhouse effect. Since the Industrial Revolution we have been systematically adding carbon dioxide and other greenhouse gasses (GHG) into the atmosphere through the burning of fossil fuels, clearing of forests, and other activities. The increased level of GHG in the atmosphere is due to these excessive emissions, which is exceeding the ecological carrying capacity with regard to the service of carbon and other nutrient cycling. After three centuries of overshoot, we are now beginning to see the degradation of our ecosystem service of climate regulation, and the effects of global warming. These effects and potential effects have been revealed by a variety of researchers, including the Nobel Laureate Intergovernmental Panel on Climate Change (IPCC) formed by the United Nations. The IPCC has provided evidence that in order to avoid dangerous interference of the Earth's climate, 
globally we need to decrease our greenhouse gas emissions by 50 percent by 2050 from 1990 levels. This would limit the global average surface temperature to a rise of no more than 2 degrees (Celsius) above pre-industrial levels, which corresponds to the highest temperature recorded from any earlier interglacial (warm) period in the Earth's history.

The IPCC recommendation is for all types of anthropogenic GHG emissions. It identifies all the major emissions sources, which can be organized into three main categories, Figure 3. Emissions from "agriculture and waste" are a byproduct of synthetic nitrogen fertilizer application, gasses produced from animal stock digestive processes and others. "Biomass decay" emissions result from clearing forests for agriculture, decay of drained soils and other land use change, and other sources. Emissions from "fossil fuel use" result from burning coal, oil, and natural gas. All of these sources contribute to an imbalance in the global carbon cycle, such that more carbon is flowing into the atmosphere than to the earth.

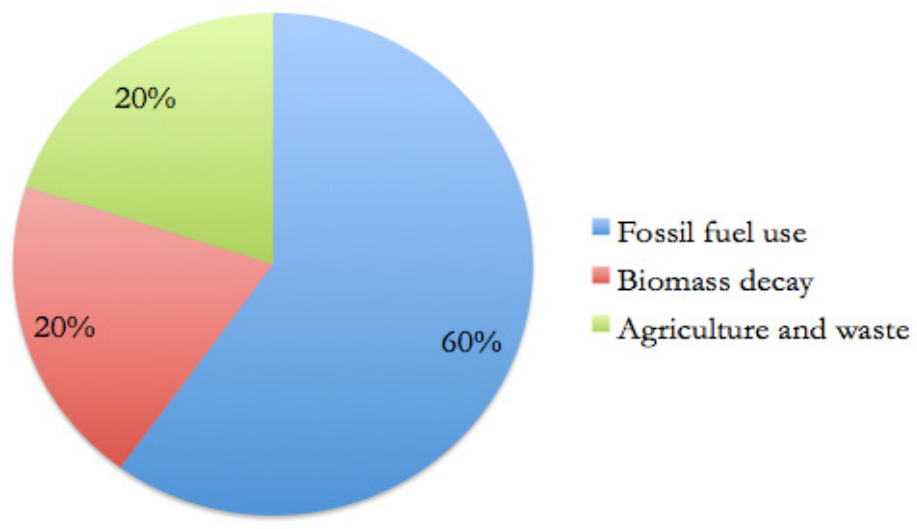

Figure 3: Current mix (rounded to nearest 10\%) of global GHG emissions by source [3].

An imbalance in the carbon cycle can be quantified using the parts-permillion (ppm) metric. This metric describes the concentration of greenhouse gasses in the atmosphere. The IPCC recommendation for emissions reduction is meant to stabilize the concentration of GHGs at $450 \mathrm{ppm}$. The IPCC recommendation to reduce emissions 50 percent by 2050 provides a timeline for global emissions reduction. This recommendation has provided and continues to provide guidance for nations setting emissions reduction goals, however, when we envision a goal based on staying within the limits of carrying capacity, the ultimate reduction is likely greater. Such a goal would require us to completely eliminate anthropogenic GHG emissions. In effect, this would create a situation of net zero carbon flow from the earth to the atmosphere, thus returning balance to the global carbon cycle. 
A societal goal of net zero carbon provides a unique opportunity for building sustainability assessment. It allows us to set a goal that is not relative to other buildings, unlike all existing carbon emissions goals, but to an estimate of sustainability itself. A building project with net zero carbon flow is what we call "Carbon Neutrality."

\subsection{Calculating carbon neutrality}

Calculating carbon neutrality involves an estimate of net carbon flow each year as a result of the construction of the new building, over the course of the building lifetime. We recognize that there are two ways that carbon flows on a net annual basis: either from the earth to the atmosphere, such as through the burning of ancient vegetation (i.e., fossil fuels), or vice versa, such as through the restoration of a forest. There are two major steps involved with calculating net annual carbon flow. The first is to draw a boundary of analysis around the building and estimate the emissions from the various sources. This boundary of analysis will likely not capture everything that should be captured, so we are underestimating our GHG emissions. With regard to the classifications of the GHG Protocol, the Green Footstep tool accounts for emissions classified as Scope 1 (direct emissions), Scope 2 (indirect emissions associated with purchased electricity, heat or steam), and Scope 3 (all other emissions, including embodied emissions). The specific emissions accounted for within each Scope category are explained below. The second major step has to do with offsetting emissions. Emissions can be offset with on-site renewable energy and investment in off-site carbon emissions reductions (or "off-site carbon investments"). More on offsetting emissions can be found in a subsequent section.

There are at least four major GHG emissions sources arising from building developments. The first is regarding the development of the site. The second is the embodied emissions from construction, retrofits, and demolition. The third is the operation of the building. The fourth aspect is the transportation to and from the building. The Green Footstep calculator currently accounts for, at least in part, the first three of these four aspects. We anticipate that subsequent versions of the calculator will account for the transportation aspect, which takes on a special dimension with developments such as Smart Garage and Plug-In Hybrid Electric Vehicles. These four aspects are described in successive sections.

\subsection{Site development and net site carbon storage}

Accounting for the carbon emissions as a result of development of the site requires comparing the native carbon storage of the site to the storage after the site is developed. Site development typically results in a net positive carbon flow from the earth to the atmosphere. This phenomenon is perhaps most well known in the context of forest depletion and other land use change. For instance, forests in Africa are becoming smaller due to increased consumption of wood for cooking. Carbon intensive rain forests in South America are being converted to less intensive farmland. Using the same method developed by the IPCC to 
account for this depletion in carbon storage, we can calculate the emissions associated with land development for buildings and urban sprawl [4].

In order to understand this concept of carbon storage, it is best that we reach out to the discipline of chemistry. The main idea is that each molecule in a plant contains a certain number of carbon $(\mathrm{C})$ atoms. Carbon makes up roughly half the dry mass of vegetation. Ecologists have already gathered data to estimate the total weight of vegetation per hectare for different ecosystems. They have shown that the mass of vegetation ebbs and flows with each season in some ecosystems, with the greatest mass toward the end of the growing season, as you might expect. In the case of deciduous trees, for instance, significant loss of mass occurs with the loss of leaves for the winter season.

This mass returns during the spring and summer seasons, and the cycle continues. There is a concurrent cycle of dying and sprouting of trees and other plants. Over the course of several generations of trees and other vegetation, we know how much carbon is typically stored per acre of the ecosystem. If we think back to a time when there were no buildings, the native vegetation on those sites stored a certain amount of carbon. By simply removing that vegetation to make room for buildings and pavement, we are decreasing the ability of the earth to sequester and store carbon.

Studies of carbon storage specific to land types have already been gathered by the IPCC for a variety of forests and grassland. This data is preliminary and will likely be updated as more studies are made. For instance, current data only accounts for above ground biomass. In some ecosystems, up to 80 percent of total biomass is located below ground. Building professionals will need to reach out to the field of ecology to stay up to date as to the amount of carbon emitted due to site development.

\subsection{Embodied emissions}

In addition to accounting for the development of the site, we need to account for the so-called embodied carbon emissions as a result of the construction, retrofit and demolition of the building. (The Green Footstep tool currently does not account for the retrofit and demolition of the building.) About eight percent of all energy consumed in the U.S. falls into this category. Using a method known as Life Cycle Assessment (LCA) we can trace back all the energy used and the resulting carbon emissions from the extraction of raw materials, materials processing, assembly or demolition of materials on the construction site, and the transportation involved throughout this series of events. These emissions can be minimized by using recycled and salvaged materials, achieving the same design objectives using fewer materials, and purchasing local materials to reduce transportation.

For projects in the United States, emissions intensity for different space types was derived using an Economic Input Output LCA approach. Results from the Athena Institutes' EcoCalculator can be input to estimate an overall reduction from average. An explanation of this method can be found in a forthcoming study and is available from Rocky Mountain Institute upon request. 


\subsection{Operation emissions}

The emissions as a result of building operation can be divided into two major areas. One is the provision of thermal comfort, indoor air quality and lighting. This area typically represents the greatest portion of carbon flow as a result of a building throughout its lifetime. The second area is the provision of fresh water, the handling of waste (including wastewater) generated by building occupants and refrigeration leak. While the second area is a significant source of emissions, the current version of Green Footstep does not estimate these for users. These emissions can be reduced through efficient water fixtures, on-site water treatment (such as the EcoMachine or Living Machine) use of low Global Warming Potential refrigeration fluid, and a recycling system and composting.

The emissions from area one, defined above, are measured for each type of energy required to provide those services. Whether the fuel is district steam, natural gas, electricity, or another, you can estimate the emissions using standard emissions coefficients available from the U.S. Environmental Protection Agency or other sources. Designers can minimize this source of emissions with a climate responsive building design that incorporates a variety of strategies for a very high level of energy efficiency. In RMI's experience, the best and most costeffective way to handle this is, in the following order: define the end-use service first, not the amount of equipment required; reduce loads through passive design; use efficient systems and equipment to meet these loads; turn down or switch off equipment when not required (controls) and continuously monitor and verify performance.

It is important to acknowledge the fact that the rate of GHG emissions associated with use of electricity will likely decrease with time. The Green Footstep tool currently does not account for this decrease. A subsequent version of the tool will include this aspect.

\subsection{Transportation emissions}

The transportation of people to and from a building is influenced by a number of factors, including number of parking spaces and distance to mass transit stops. Perhaps the greatest effect a building designer can have on transportation is by providing a limited number of car parking spaces, bike racks, a shower room for those who bike, and plug-in stations for an emerging fleet of Plug-in Hybrid Electric Vehicles. The current version of Green Footstep does not account for this aspect of emissions. We expect to incorporate this into a future version.

\section{Strategies to offset emissions}

In addition to accounting for the emissions of a building project, including the effects of a an energy efficient design, the Green Footstep calculator reveals two main ways in which building stakeholders can offset these emissions. One is onsite renewable energy, which prevents the use of off-site energy that is typically 
and in large part, at least currently, fossil fuel based. The second is investment in off-site carbon emissions reductions, or off-site carbon investments.

\subsection{On-site renewable energy}

On-site renewable energy can take the form of electricity or thermal energy. Typically, photovoltaic panels and wind turbines are integrated into the building design to produce a portion or all of the electricity required by the building without sacrificing, and sometimes augmenting, the architecture. Solar thermal panels and geothermal heat pumps can provide thermal energy in a costeffective, efficient way. There are a variety of building integrated renewable energy products on the market for any building size and type.

The Green Footstep calculator balances the would-be emissions of required energy with the "offset" emissions by the on-site renewable energy. The emissions coefficients for each incoming energy and on-site energy can be found on the "Operation" table of the calculator.

The emissions coefficient of on-site renewable electricity equals that of offsite electricity, such that if the building uses $30 \mathrm{MWh}$ of electricity each year and produces the same amount of electricity, the net emissions is zero. Regarding thermal energy, the rate of emissions offset is equivalent to the emissions rate of the fuel it is replacing. For instance, if the auxiliary fuel for hot water heating is natural gas, the solar thermal application should offset the emissions required for this energy load at the same emissions intensity of natural gas. The user specifies this auxiliary fuel.

\subsection{Off-site carbon investments}

Off-site carbon investments can be organized into two categories: off-site renewable energy investments and carbon offsets.

Off-site renewable energy. There are a couple of ways of purchasing carbonfree electricity to meet a building's needs. Individuals or organizations could buy renewable energy directly from their utility if available. Alternatively, stakeholders could buy Renewable Energy Credits, or RECs, which represent all of the environmental attributes of renewable generation. This means that the environmental benefits of purchasing RECs are equivalent to the environmental impacts of purchasing renewable energy directly. Purchasers can maximize the impact of their RECs by ensuring that they are supporting renewable energy that would not have been installed otherwise. You can accomplish this by purchasing certified RECs from states where electric utilities are already required to buy renewable power. RECs generated in such states are in addition to any renewables that would have been installed anyway for economic reasons or for regulatory compliance. One source of such RECs (and of additional information on RECs and offsets) is Village Green Energy.

Carbon offsets. A carbon offset is a real, verifiable, permanent reduction of GHG emissions that occurs above and beyond expected or required reductions. In recent years a carbon offset market has emerged internationally. Through the market, individuals and organizations can purchase credits that negate a portion 
or all of their GHG emissions. Types of carbon offset credits vary widely. Specifically, there are many different kinds of projects that can reduce carbon concentrations in the atmosphere. These could include projects promoting additional efficiency measures or use of renewables, or they could include capturing methane, or planting trees for instance. While individuals and organizations may have particular preferences about the type and location of the offsets they purchase, they should always select quality offsets. This means that offsets should be real -i.e., they are actual reductions in total GHGs emitted globally and are not, for instance, just displacement of emissions from one place to another. The offsets should also be clearly calculated, tracked and verified. They should be reductions that are guaranteed to be permanent. Finally, offsets should also represent reductions that occur in addition to what would have happened in the absence of the offset purchase - i.e. reductions were not implemented for regulatory reasons nor did they occur simply as a result of an economic downturn for instance.

There are some certifications and third parties that can help individuals and organizations identify quality offsets. One such resource is Environmental Defense's Carbon Offset List where the organization publishes projects they have pre-screened and approved.

\subsection{Selecting offset strategies}

The Green Footstep calculator does not make a blanket recommendation that one emissions offset strategy is better than another. On a case-by-case basis, developers and building owners should evaluate both on-site and off-site strategies within a financial model based on Life Cycle Cost Analysis (i.e., the evaluation of capital and operating costs to calculate net present value or internal rate of return of alternate sets of building design options). Other forms of value that should be considered but are more difficult to quantify include added building resale value, value of building energy autonomy, and value to community for investment in renewable energy.

\section{Ecological accounting}

The idea of a net zero carbon flow over the course of a building lifetime is analogous to financial planning. Owners of buildings own much more than just buildings. In a way they also "own" and should be responsible for the carbon that would have been stored on the site in its native, natural form. We can estimate this value using data from the IPCC. The Green Footstep calculator defines this value as the carrying capacity limit of the building site. In order to stay within carrying capacity, the cumulative emissions over the course of the building lifetime need to reach or exceed this carbon storage value.

Carbon storage can be considered a form of natural capital. When a building is first constructed, this capital is "spent" through site disturbance. Embodied emissions of construction also represent the spending of carbon storage capital. These emissions can be 5 times or more (typically much more) than the amount 
of carbon originally stored on site. Likewise, any carbon emissions during the course of building operation contribute to the "carbon debt." After the lifetime of the building, these operation emissions can be 5-15 times that of the embodied emissions.

In this paradigm of building assessment, the operation of a building can either drive the building further into debt or, by reducing and offsetting carbon emissions, the debt can be paid back. As soon as the debt is repaid, the building development has reached carbon neutrality. Figure 4 below illustrates this concept, which we also call an "ecological mortgage." The green (top, horizontal) dashed line represent the net site carbon storage in its native state. Below this line represents a net flow of GHGs into the atmosphere. Above the line represents a net flow from the atmosphere to the earth. The red (downward sloping, bottom) line represents standard performing buildings. They incur an initial debt from site development and building construction. Then they begin to operate and go into greater carbon debt. There are major retrofit projects that occur along the way as well (denoted in the chart), which contributes to the debt. The orange (horizontal, stepped) line is a net zero carbon emissions building during operation. However, as shown in the chart, it remains in carbon debt due

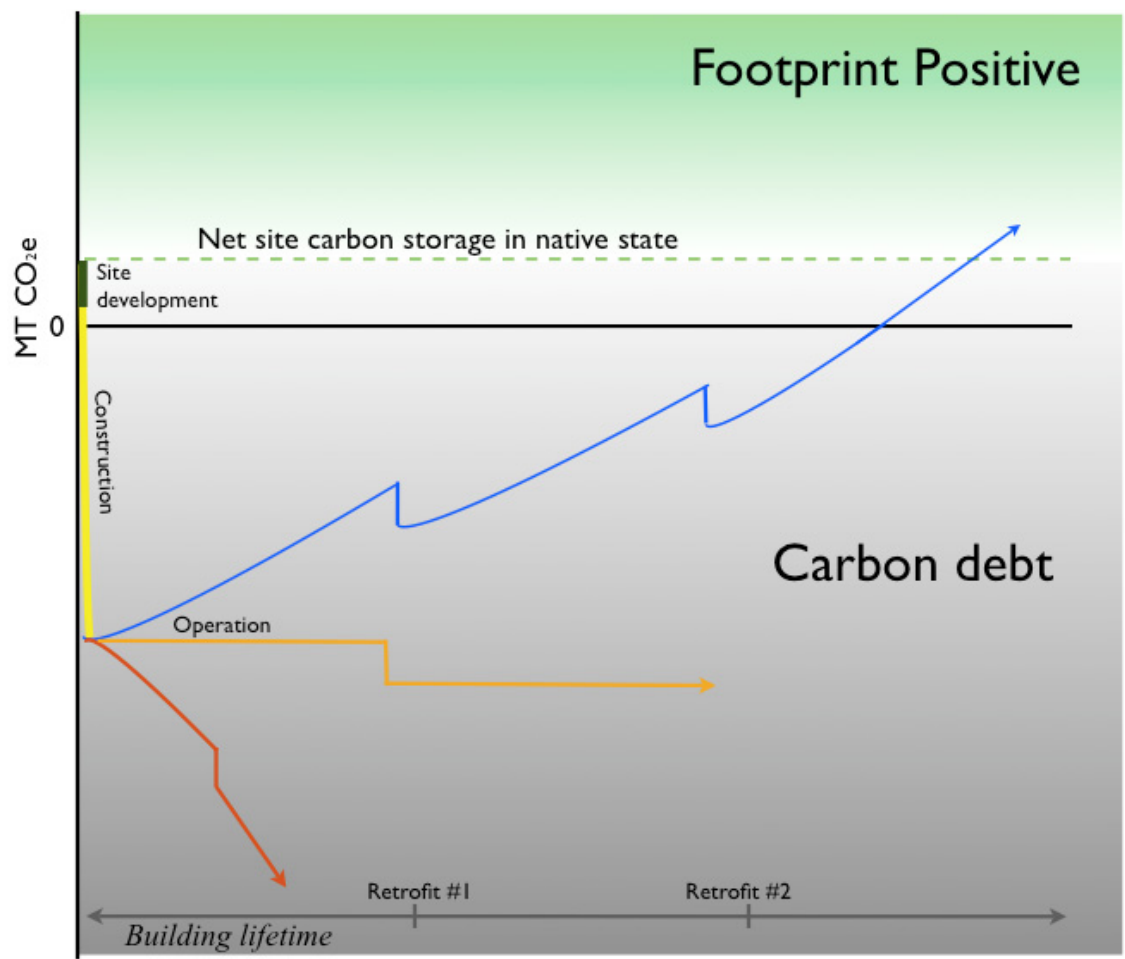

Figure 4: Illustration of ecological mortgage concept. 
represents a building that, through energy efficiency and the offset of carbon, has surpassed carbon neutrality and is "Footprint Positive." This is the ideal form of assessment for which we have designed Green Footstep. The current version of the tool does not account for the illustrated retrofits.

The "ecological mortgage" concept can be directly related to a global target of no more than $450 \mathrm{ppm}$ of GHGs in the atmosphere. The cumulative emissions by the end of building lifetime - which is an output of the Green Footstep tool is the amount by which the building has contributed to an increase in global GHG concentration. So, in effect, Figure 3 above can be restated in the following way "A typical building (red line) continually contributes to a higher global concentration of GHGs in the atmosphere. A regenerative building (blue line) reaches above the "Line of neutral contribution to global ppm" to contribute to the decrease of global GHG ppm.

Addressing the atmospheric carbon associated with buildings is critical to reducing the impacts of global climate change. The calculations associated with this issue are not complicated, but are typically not done. Green Footstep provides an accurate, comprehensive and easy to use tool that allows decisions to be made during the design process to encourage the development of high performance, very-low carbon designs. Broad use of tools such as Green Footstep may assist in the development of high performance buildings appropriate for an ecologically constrained world.

\section{References}

[1] Wackernagel, Mathis \& Rees, William, Our Ecological Footprint, New Society Press, 1996

[2] Millennium Ecosystem Assessment, Ecosystems and Human Well-being: Synthesis, Island Press, Washington, DC, pp vi, 2005

[3] Barker T., I. Bashmakov, L. Bernstein, J. E. Bogner, P. R. Bosch, R. Dave, O. R. Davidson, B. S. Fisher, S. Gupta, K. Halsnaes, G.J. Heij, S. Kahn Ribeiro, S. Kobayashi, M. D. Levine, D. L. Martino, O. Masera, B. Metz, L. A. Meyer, G.-J. Nabuurs, A. Najam, N. Nakicenovic, H. -H. Rogner, J. Roy, J. Sathaye, R. Schock, P. Shukla, R. E. H. Sims, P. Smith, D. A. Tirpak, D. Urge-Vorsatz, D. Zhou, 2007: Technical Summary. In: Climate Change 2007: Mitigation. Contribution of Working Group III to the Fourth Assessment Report of the Intergovernmental Panel on Climate Change [B. Metz, O. R. Davidson, P. R. Bosch, R. Dave, L. A. Meyer (eds)], Cambridge University Press, Cambridge, United Kingdom and New York, NY, USA

[4] Keith Paustian (USA), N.H. Ravindranath (India), and Andre van Amstel (Netherlands), Michael Gytarsky (Russian Federation), Werner A. Kurz (Canada), Stephen Ogle (USA), Gary Richards, (Australia), and Zoltan Somogyi (European Commission/Hungary), 2006 IPCC Guidelines for National Greenhouse Gas Inventories Volume 4 Agriculture, Forestry and Other Land Use, 2006 